\title{
Loss of the metastasis suppressor gene KiSS1 is associated with lymph node metastasis and poor prognosis in human colorectal cancer
}

\author{
YOSHINAGA OKUGAWA, YASUHIRO INOUE, KOJI TANAKA, YUJI TOIYAMA, TADANOBU SHIMURA, \\ MASATO OKIGAMI, AYA KAWAMOTO, JUNICHIRO HIRO, SUSUMU SAIGUSA, \\ YASUHIKO MOHRI, KEIICHI UCHIDA and MASATO KUSUNOKI
}

\begin{abstract}
Department of Gastrointestinal and Pediatric Surgery, Division of Reparative Medicine, Institute of Life Sciences, Mie University Graduate School of Medicine, Tsu, Mie 514-8507, Japan
\end{abstract}

Received March 4,2013; Accepted May 2, 2013

DOI: $10.3892 /$ or.2013.2558

\begin{abstract}
Cancer research is currently focused on blocking the metastatic process at its early steps. Some particularly attractive targets are metastasis suppressor genes, which control cancer cell dissemination. The aim of this study was to clarify the relationship between the expression of KiSS1, a metastasis suppressor gene, and disease progression in colorectal cancer patients. One-hundred and seventy-five patients who underwent surgery for colorectal cancer were enrolled in this study. We analyzed KiSS1 mRNA expression by real-time reverse transcription PCR in colorectal cancer tissue and paired adjacent normal mucosa. KiSS1 protein expression in early- and advanced-stage colorectal cancer samples was determined by immunohistochemical analysis. Decreased KiSS1 expression was significantly associated with lymph node metastasis and was an independent prognostic factor. Logistic regression analysis revealed that decreased KiSS1 expression was an independent risk factor for lymph node metastasis. Immunohistochemical analysis indicated that KiSS1 was highly expressed in the cell cytoplasm of early-stage colorectal cancer cells. The loss of KiSS1 appears to correlate with the progression of lymph node metastasis. An assessment of KiSS1 expression may assist in the accurate colorectal cancer diagnosis and may contribute to predict clinical outcomes.
\end{abstract}

\section{Introduction}

Metastasis is a characteristic event in cancer progression and a critical determinant in the prognosis of patients with malignant disease. The process involved in the initiation of metastasis from malignant tumors, such as in colorectal carcinoma,

Correspondence to: Professor Masato Kusunoki, Department of Gastrointestinal and Pediatric Surgery, Division of Reparative Medicine, Institute of Life Sciences, Mie University Graduate School of Medicine, 2-174 Edobashi, Tsu, Mie 514-8507, Japan E-mail: yosinaga@clin.medic.mie-u.ac.jp

Key words: KiSS1, colorectal cancer, lymph node metastasis consists of multiple steps. During metastasis, tumor cells first migrate through the stroma, invade a vessel to enter the circulation, then adhere to the microvascular endothelium, before finally extravasating and proliferating in the target organ (1-4). Each step has been investigated for the purpose of establishing targeted antimetastatic agents.

Metastasis suppressor genes represent a new gene family involved in the pathogenesis of malignant progression in various types of cancer (5). These genes have been suggested to contribute to key steps during metastasis.

KiSS1 was first described as a metastasis suppressor in human melanoma and breast cancer (6-8). KiSS1 encodes a 145 amino-acid protein, which is processed into kisspeptin (also known as a metastin) of several sizes (9-11). The KiSS1 gene product was isolated from human placenta and an endogenous ligand was used to bind a G-protein-coupled receptor known as GPR54 (10). A correlation has been shown between the loss of KiSS1 expression and cancer progression as well as poor prognosis in esophageal squamous cell carcinoma (12), gastric (13), pancreatic (14), bladder (15), ovarian (15) and breast cancer (16).

Although a growing number of studies have demonstrated the function of KiSS1 in experimental systems, no reports have shown any clinical relationship between KiSS1 expression and cancer progression in colorectal cancer. The aim of this study was to clarify the clinical significance of KiSS1 expression in colorectal cancer.

\section{Materials and methods}

Patients and sample collection. A total of 175 patients ( 99 men, 76 women) with a mean age of 67 years (range 12-91 years) who underwent surgery for colorectal cancer from November 2000 to October 2006 at Mie University Hospital, Japan, were enrolled in the study. Fresh frozen surgical cancer samples, for which complete clinical data and isolated RNA of sufficient quality for real-time PCR were available, were obtained from the patients. No patients had received anticancer therapy prior to surgery and there were no perioperative mortalities among these patients. 
The locations of tumors and distant metastases were determined by barium enema, colonoscopy, computerized tomography (CT) and magnetic resonance imaging (MRI). The location of the primary lesion was in the rectum in 57 patients, the sigmoid colon in 63 patients, the ascending colon in 38 patients, the transverse colon in 13 patients and the descending colon in 4 patients. Forty-one of the 175 patients had synchronous distant metastasis (liver, lung and peritoneum) at the time of surgery. Resection of the primary tumor was performed in all patients and simultaneous partial hepatectomy for liver metastasis was performed in 9 of these 27 patients. Only 16 patients had poorly differentiated adenocarcinoma, whereas 159 patients had either well or moderately differentiated adenocarcinoma. All patients were classified according to UICC staging of resected specimens. Overall, 39 patients had UICC stage I (T1-2NOM0) disease, 51 patients had UICC stage II (T3-4N0M0) disease, 44 patients had UICC stage III (TXN1-2M0) disease and 41 patients had UICC stage IV (TXNXM1) disease. Stage III and IV patients received fluorouracil-based chemotherapy, whereas no adjuvant therapy was given to stage I or II patients. Patients were observed at 3-month intervals for 24 months after surgery, then every 6 months for 3 years and then on an annual basis. A history was obtained and a physical examination was performed at each visit. Chest X-rays, colonoscopies and CTs were performed annually. The median follow-up time was 43.2 months (mean, $43.2 \pm 29.8$ months).

Among the 175 patients evaluated, 40 patients died due to primary or recurrent disease. Matched control samples were acquired from adjacent normal mucosa located far from the tumor site. These samples were frozen in liquid nitrogen immediately after surgical resection and were stored at $-80^{\circ} \mathrm{C}$ until RNA extraction. The purpose of this study was to analyze KiSS1 expression made post hoc using previously and prospectively collected tissue samples. Written informed consent was obtained from all patients. The diagnosis of colorectal cancer was confirmed in all 175 patients on the basis of clinicopathological findings.

Total RNA extraction and cDNA synthesis. Tumor specimens were homogenized with a Mixer Mill MM 300 homogenizer (Qiagen, Chatsworth, CA, USA). Total RNA was isolated using an RNeasy Mini kit (Qiagen), used according to the manufacturer's instructions. cDNA was synthesized from $5.0 \mathrm{mg}$ of RNA with random hexamer primers and Superscript ${ }^{\mathrm{TM}}$ III reverse transcriptase (Invitrogen, Carlsbad, CA, USA) used according to the manufacturer's instructions.

Real-time quantitative RT-PCR. Quantitative PCR (qPCR) analysis was performed using the TaqMan ${ }^{\circledR}$ Universal PCR Master Mix (Applied Biosystems, Foster City, CA, USA). The relative abundance of target transcripts, measured using TaqMan ${ }^{\circledR}$ probes for KiSS1 (Hs00158486_m1, TaqMan ${ }^{\circledR}$ Gene Expression Assays; Applied Biosystems) was normalized to the expression level of $\beta$-actin (Hs99999903_m1, TaqMan ${ }^{\circledR}$ Gene Expression Assays; Applied Biosystems) and measured using Applied Biosystems StepOne ${ }^{\mathrm{TM}}$ Software v2.1. All reactions for standard samples and for patient samples were performed in triplicate. The data were averaged from the values obtained in each reaction.
Immunohistochemical analysis. Immunohistochemical analysis of KiSS1 protein expression was performed on colorectal cancer surgical specimens using avidin-biotin peroxidase methods (DakoCytomation, Carpinteria, CA, USA) on formalin-fixed, paraffin-embedded tissues. All sections were counterstained with hematoxylin. A primary rabbit polyclonal antibody against KiSS1 (sc101246; Santa Cruz Biotechnology, Inc., Santa Cruz, CA, USA) was used at a dilution of 1:50.

Statistical analysis. Statistical analysis was performed using StatView software (version 5; Abacus Concepts, Inc., Berkeley, CA, USA). Results are expressed as the means \pm standard deviation (SD) and differences were evaluated by the Wilcoxon rank correlations test. Mann-Whitney U tests were used to evaluate differences between unpaired observations. Analyses of nonparametric receiver operating characteristics (ROCs) were performed to calculate the cut-off values according to the most accurate value obtained using MedCalc 7.2 for Windows (MedCalc, Mariakerke, Belgium). Actuarial survival curves were obtained using the Kaplan-Meier method and comparisons were made using log-rank tests. The Cox proportional hazards regression model was used for multivariate analysis after the relevant prognostic variables had been defined by univariate analysis. Logistic regression analysis was used to evaluate the independent influence of factors on peritoneal dissemination as the final outcome. Two-sided P-values $<0.05$ were considered to indicate statistically significant differences.

\section{Results}

Overexpression of the KiSS1 gene in colorectal cancer. Expression values (relative mRNA levels) of KiSS1 were expressed as ratios between the gene of interest (KiSS1) and an internal reference gene ( $\beta$-actin), which provided a normalization factor for the amount of RNA. In clinical samples obtained from patients with colorectal cancer, quantitative real-time RT-PCR revealed that the mean KiSS1 mRNA expression level in cancerous tissues was significantly higher than that in corresponding adjacent normal mucosa (cancerous tissue, 373.2 \pm 1129.6 ; adjacent normal mucosa, $0.06 \pm 0.12 ; \mathrm{P}<0.001$ ) (Fig. 1A). In addition, the mean level of KiSS1 expression was likely to decrease in a stage-dependent manner (Fig. 1B).

Clinical significance of KiSS1 expression in colorectal cancer. Table I shows clinicopathological variables and KiSS1 mRNA expression levels in tumor specimens from colorectal cancer patients. The KiSS1 expression level was significantly associated with lymph node metastasis. In the entire colorectal cancer population, the best pair of values for highest sensitivity (58.5\%) and highest specificity (61.9\%) was found using a peak KiSS1 mRNA expression cut-off point of 9.276. Patients with KiSS1 expression levels $<9.276$ in cancerous tissues were assigned to the low-expression group $(\mathrm{n}=75)$, whereas those with values $\geq 9.276$ were assigned to the high-expression group $(n=100)$. Patients in the low-expression group had significantly poorer prognoses than those in the high-expression group (log-rank test, $\mathrm{P}=0.014$ ) (Fig. 2). 
Table I. Clinicopathological variables and KiSS1 mRNA expression in 175 colorectal cancer patients.

\begin{tabular}{cccc}
\hline & \multicolumn{2}{c}{$\begin{array}{c}\text { KiSS1 mRNA } \\
\text { expression }\end{array}$} \\
Variable & $\mathrm{n} \quad \begin{array}{c}\text { High } \\
(\mathrm{n}=100)\end{array} \stackrel{\text { Low }}{(\mathrm{n}=75)}$ & P-value \\
& &
\end{tabular}

\section{Gender}

Male

$\begin{array}{lll}99 & 60 & 39\end{array}$

0.291

Female

$\begin{array}{lll}76 & 40 & 36\end{array}$

Age (years)

$$
\begin{aligned}
& <67 \text { (median) } \\
& \geq 67
\end{aligned}
$$

$\begin{array}{lll}76 & 40 & 36 \\ 99 & 60 & 39\end{array}$

Tumor location

$$
\text { Colon }
$$

Rectum

$\begin{array}{rrr}118 & 64 & 54 \\ 57 & 36 & 21\end{array}$

Tumor size $(\mathrm{cm})$

$$
\begin{aligned}
& \geq 4.5 \text { (median) } \\
& <4.5
\end{aligned}
$$

$\begin{array}{lll}86 & 50 & 36 \\ 89 & 50 & 39\end{array}$

0.793

Histological type

Differentiated

Undifferentiated

$\begin{array}{rrr}159 & 93 & 66 \\ 16 & 7 & 9\end{array}$

0.256

Pathological T category

T1

$\mathrm{T} 2$

T3

$\mathrm{T} 4$

Venous invasion

$$
+
$$$$
-
$$

Lymphatic invasion

$$
+
$$$$
-
$$$$
15
$$$$
21 \quad 15
$$$$
25 \quad 14
$$$$
97 \quad 52
$$$$
32 \quad 19
$$

$$
9
$$

39

39$$
-
$$$$
\begin{array}{lll}
19 & 12 & 7
\end{array}
$$

Lymph node metastasis

$\begin{array}{lrrrr}- & 106 & 68 & 38 & 0.020^{\mathrm{a}} \\ + & 69 & 32 & 37 & \end{array}$

Hepatic metastasis

\begin{tabular}{lrrrr}
- & 148 & 87 & 61 & 0.304 \\
+ & 27 & 13 & 14 & \\
Pulmonary metastasis & & & & \\
- & 156 & 91 & 65 & 0.362 \\
+ & 19 & 9 & 10 & \\
Peritoneal dissemination & & & & \\
- & 171 & 98 & 73 & 0.771 \\
+ & 4 & 2 & 2 & \\
\hline
\end{tabular}

Pearson's Chi-square test was used for all analyses. ${ }^{\mathrm{a}} \mathrm{P}<0.05$.

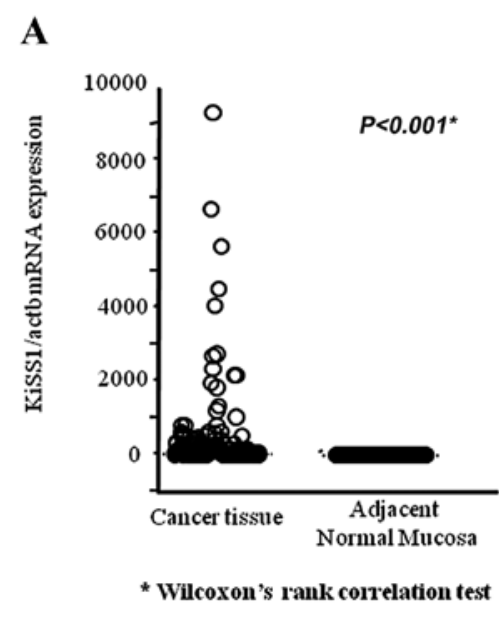

B

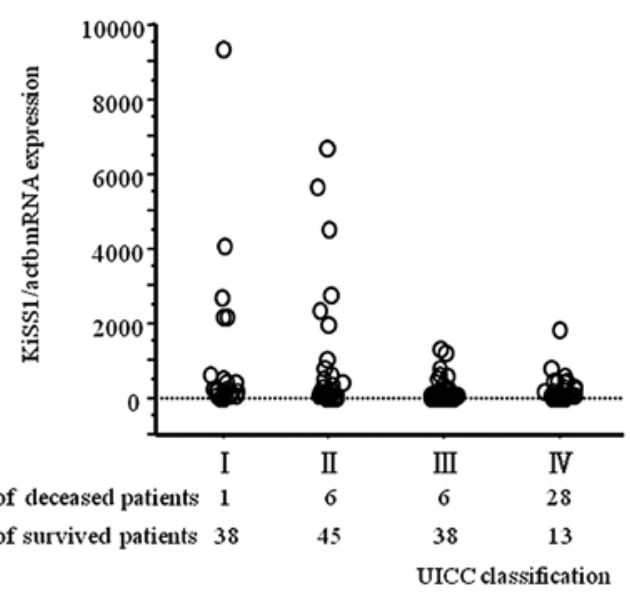

Figure 1. (A) Quantitative real-time RT-PCR was performed on 175 colorectal cancer samples and paired adjacent normal mucosa samples. KiSS1 expression was significantly higher in cancer samples than in adjacent normal mucosa ( $\mathrm{P}<0.001$; Wilcoxon rank correlation test). (B) Scattergram of KiSS1 mRNA expression with UICC classification in 175 colorectal cancer patients.

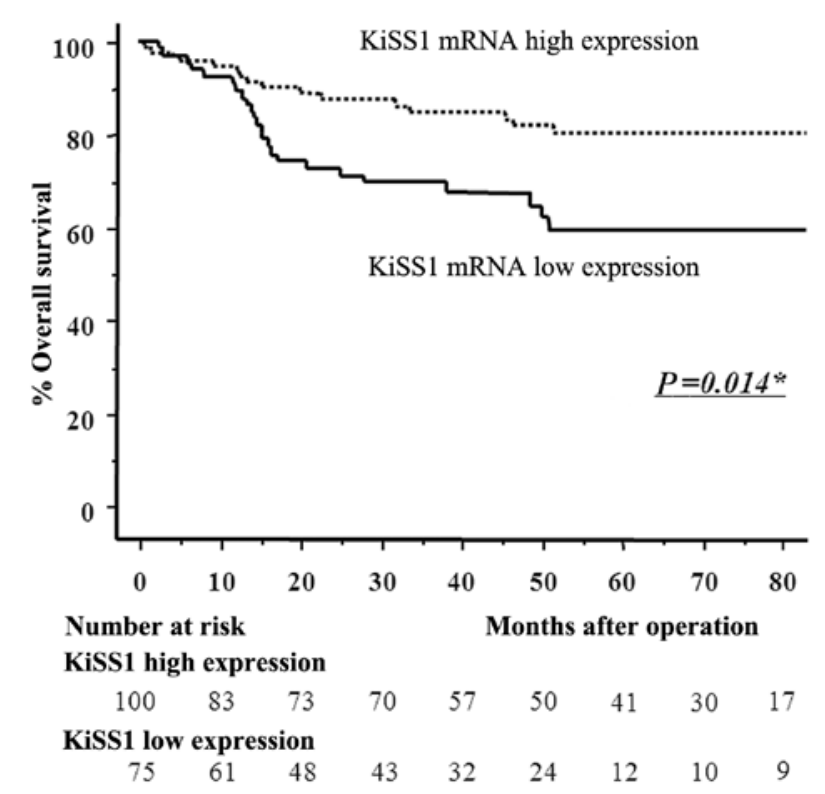

Figure 2. Kaplan-Meier survival curves for the 175 colorectal cancer patients according to their KiSS1 expression level. Patients with low KiSS1 mRNA expression had a significantly poorer prognosis than those with high KiSS1 mRNA expression $(\mathrm{P}=0.014$; log-rank test). 
Table II. Multivariate analysis for predictors of survival.

\begin{tabular}{|c|c|c|c|c|c|c|}
\hline \multirow[b]{2}{*}{ Variable } & \multicolumn{3}{|c|}{ Univariate } & \multicolumn{3}{|c|}{ Multivariate } \\
\hline & HR & $95 \% \mathrm{CI}$ & P-value & HR & $95 \% \mathrm{CI}$ & P-value \\
\hline Tumor size [ $\geq 4.4 \mathrm{~cm}$ (median)] & 1.79 & $0.95-3.35$ & 0.07 & & & \\
\hline T classification (pT3/4) & 18.5 & $2.53-142.8$ & $0.004^{\mathrm{a}}$ & 14.93 & $1.89-125$ & $0.011^{\mathrm{a}}$ \\
\hline Histological type (differentiated type) & 0.77 & $0.30-1.95$ & 0.576 & & & \\
\hline Lymphatic invasion (present) & 5.75 & $0.79-41.7$ & 0.084 & & & \\
\hline Venous invasion (present) & 3.58 & $1.11-116.3$ & $0.033^{\mathrm{a}}$ & 0.96 & $0.28-3.29$ & 0.951 \\
\hline Node involvement (present) & 3.10 & $1.65-5.81$ & $<0.001^{\mathrm{a}}$ & 1.94 & $1.02-3.69$ & $0.044^{\mathrm{a}}$ \\
\hline Low KiSS1 expression & 2.15 & $1.15-4.02$ & $0.016^{\mathrm{a}}$ & 1.91 & $1.01-3.58$ & $0.045^{\mathrm{a}}$ \\
\hline
\end{tabular}

${ }^{\mathrm{a}} \mathrm{P}<0.05$. HR, hazard ratio; $\mathrm{CI}$, confidence interval.

Table III. Multivariate analysis for lymph node metastasis.

\begin{tabular}{lccccccc}
\hline & \multicolumn{3}{c}{ Univariate } & & \multicolumn{3}{c}{ Mutivariate } \\
\cline { 2 - 3 } Variable & Odds ratio & $95 \% \mathrm{CI}$ & P-value & & Odds ratio & 95\% CI & P-value \\
\hline Tumor Size $[\geq 4.4 \mathrm{~cm}$ (median) & 1.80 & $0.97-3.32$ & 0.061 & & & \\
T classification (pT3/4) & 6.36 & $2.52-16.1$ & $<0.001^{\mathrm{a}}$ & & 4.55 & $1.57-13.2$ & $0.005^{\mathrm{a}}$ \\
Histological type (differentiated type) & 0.47 & $0.17-1.33$ & 0.154 & & & \\
Lymphatic invasion (present) & 6.40 & $1.43-28.7$ & $0.015^{\mathrm{a}}$ & & 1.02 & $0.15-6.88$ & 0.983 \\
Venous invasion (present) & 4.34 & $1.70-11.1$ & $<0.001^{\mathrm{a}}$ & & 2.32 & $0.74-7.29$ & 0.149 \\
Low KiSS1 expression & 2.07 & $1.12-3.84$ & $0.021^{\mathrm{a}}$ & & 2.07 & $1.07-3.99$ & $0.031^{\mathrm{a}}$ \\
\hline
\end{tabular}

${ }^{\mathrm{a}} \mathrm{P}<0.05$. CI, confidence interval.

Loss of KiSS1 expression is correlated with lymph node metastasis and a poorer prognosis in colorectal cancer. The association between KiSS1 expression and prognosis in colorectal cancer patients was evaluated by multivariate analysis. Table II shows the resulting risk ratios and 95\% confidence intervals (CIs) calculated using the Cox proportional hazards model. Based on a Cox univariate proportional hazards analysis, advanced $\mathrm{T}$ classification (T3, T4), venous invasion, lymph node metastasis and low KiSS1 expression were associated with poor prognosis. Our multivariate analysis revealed that advanced $\mathrm{T}$ classification, lymph node metastasis and low KiSS1 expression were independent prognostic factors for colorectal cancer patients. Factors that correlated with lymph node metastasis were analyzed by logistic regression analysis (Table III). Notably, T classification and low KiSS1 expression were independent factors for lymph node metastasis in colorectal cancer patients.

Immunohistochemical staining of KiSS1 in the early and advanced stages of colorectal cancer. Immunohistochemical analysis revealed that the KiSS1 protein was predominantly expressed in the cytoplasm of primary colorectal cancer cells without expression in normal mucosa (Fig. 3A). Although KiSS1 protein was highly expressed in the early stage of colorectal cancer cells (Fig. 3B), KiSS1 expression was decreased in advanced-stage colorectal cancer tissues (Fig. 3C).

\section{Discussion}

To the best of our knowledge, this is the first study to show the relationship between KiSS1 expression and cancer progression, particularly lymph node metastasis, in colorectal cancer patients.

Metastasis suppressors regulate one or more processes in the metastatic cascade without blocking orthotopic tumor growth (17-20). Since Nm23-H1 was identified as a metastasis suppressor gene in 1988, the number of metastasis suppressor families identified has increased beyond $25(21,22)$. Studying the dysregulation of metastasis suppressor genes may help discern important cellular pathways in the metastatic behavior of various tumors and potentially suggest a new strategy for the treatment of locally advanced and metastatic cancer.

KiSS1 is one of the inhibitors identified as a human melanoma metastasis suppressor gene using subtractive hybridization between highly metastatic and nonmetastatic cell lines and respective cell line variants $(6,8)$. Transfection of full-length KiSS1 cDNA into metastatic cancer cell lines suppressed metastasis in athymic mice and supported a defined role of KiSS1 in the metastasis process (6-9). Kisspeptin is considered to possess potent antimetastatic properties and that GPR54 (KiSS-1R, hOT7T175 and AXOR12) has been detected as an orphan receptor for this protein. KiSS1/GPR54 signaling has been shown to inhibit cell motility, proliferation, invasion, chemotaxis and metastasis in various types of 

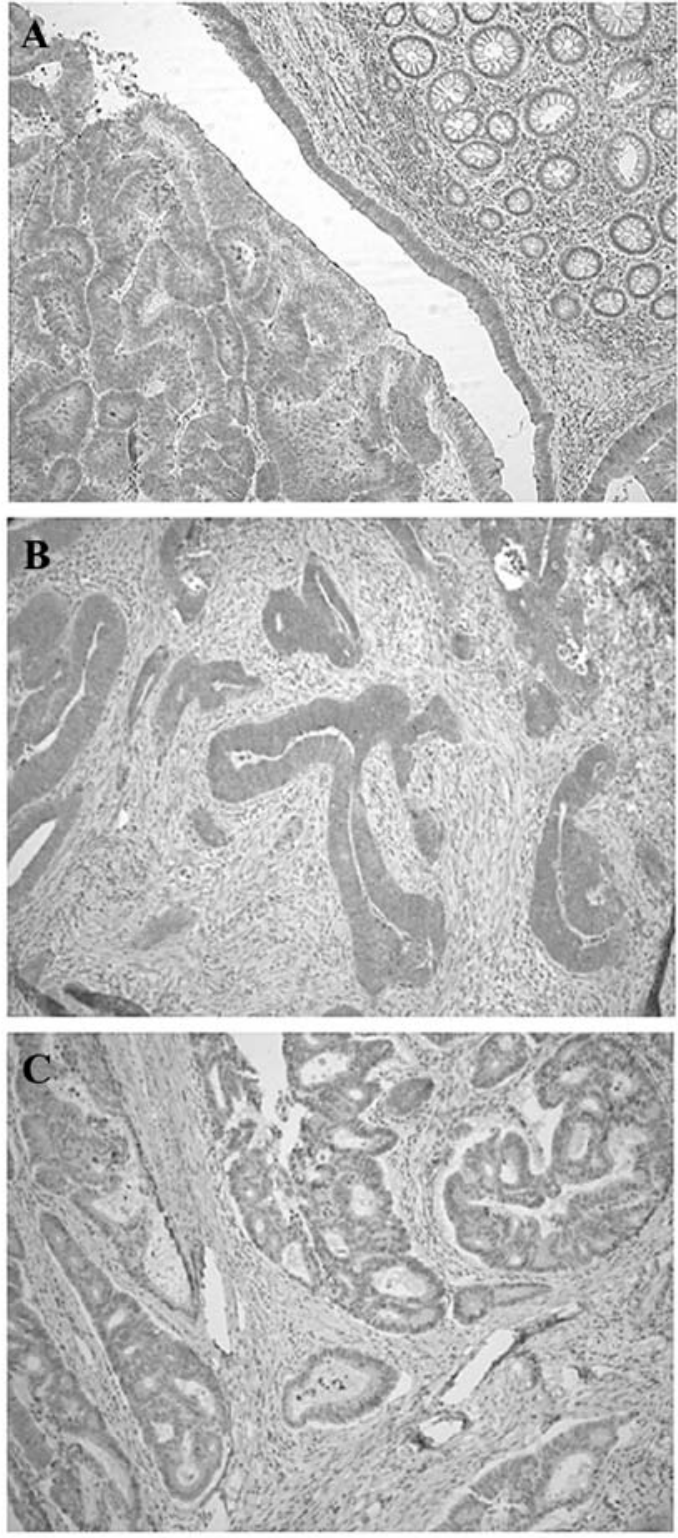

Figure 3. A typical example of immunohistochemical staining of KiSS1 (A) in colon cancerous tissue and normal mucosa, (B) in early stage, and (C) in advanced stage colorectal cancer patients (original magnification, $\mathrm{x} 100$ ).

cancer $(7,9,10,23-26)$. Although a growing number of studies have demonstrated the function of KiSS1 in various epithelial tumors, no reports have shown any clinical significance associated with KiSS1 expression in colorectal cancer.

The major finding of this study is that KiSS1 is expressed at a statistically significantly higher level in colorectal cancer tissue than in corresponding adjacent normal mucosa. Although KiSS1 expression was not clearly associated with any clinicopathological factors (tumor size, histological type, pathological $\mathrm{T}$ category, or hepatic metastasis) decreased KiSS1 expression was shown to correlate significantly with lymph node metastasis and poor prognosis. Multivariate analysis revealed that decreased KiSS1 expression is a significant independent indicator of survival. Reduced KiSS1 expression was shown to be a strong prognostic marker in patients with urinary bladder cancer and gastric cancer $(13,15)$. Our results also suggest that KiSS1 expression may be a useful tool for classification of colorectal cancer at its early stage and that loss of KiSS1 expression could be a powerful prognostic indicator in colorectal cancer patients.

This study also revealed a significant relationship between KiSS1 expression and lymph node metastasis. Metastasis to regional lymph nodes mainly affects the prognosis of non stage IV colon cancer patients $(27,28)$. The presence of lymph node metastasis in colorectal cancer is an indicator for which adjuvant chemotherapy confers significant survival benefit (29). Of note, multivariate analysis for lymph node metastasis in our study revealed that the loss of KiSS1 expression is a suitable predictor of lymph node metastasis in colorectal cancer patients. Recent reports suggest that KiSS1 may cause cancer dormancy in disseminated tumor cells at secondary sites without the colonization of ectopic tissues $(30,31)$.

KiSS1 has been shown to suppress matrix metalloproteinase-9 (MMP-9) activity (24,32). The extracellular matrix (ECM) structure is dynamic and can be degraded by the family of enzymes known as MMP. The crosstalk between dormant tumor cells and the ECM, which is regulated by stromal and tumor cells, may control the entry and exit of the cell to the dormant state. Nash and Welch (33) reported that kisspeptins bind to GPR54 and regulate events downstream of cell-matrix adhesion, perhaps involving cytoskeletal reorganization in order to block metastases through the induction of dormancy in solitary cells. In addition, Ikeguchi et al (12) also demonstrated that the loss of KiSS1 or GRP54 gene expression was a significant predictor of lymph node metastasis in esophageal squamous cell carcinoma. These reports and our results suggest that the loss of KiSS1 may be significantly involved in the pathogenesis, including the colonization steps of lymph node metastasis, in colorectal cancer. Furthermore, the analysis of KiSS1 expression using biopsy specimens may provide a more accurate evaluation to detect the absence of lymph node metastasis, which may then translate to minimally invasive treatments, such as endoscopic resection or laparoscopic assisted colectomy for early colorectal cancer.

In conclusion, we have demonstrated the clinical significance of KiSS1 expression in colorectal cancer. The loss of KiSS1 appears to play an important role in the progression of lymph node metastasis. The assessment of KiSS1 expression may assist in the accurate colorectal cancer diagnosis and may contribute to the prediction of clinical outcomes.

\section{Acknowledgements}

The authors thank Motoko Ueeda and Chihiro Hibi for their technical assistance. This study was supported in part by a Grant in Aid for Scientific Research (B: 23890083) from the Ministry of Education, Culture, Sports, Science and Technology, Japan.

\section{References}

1. Fidler IJ: Critical determinants of metastasis. Semin Cancer Biol 12: 89-96, 2002.

2. Chan DA and Giaccia AJ: Hypoxia, gene expression, and metastasis. Cancer Metastasis Rev 26: 333-339, 2007.

3. ten Kate M, Hofland LJ, van Grevenstein WM, van Koetsveld PV, Jeekel $\mathbf{J}$ and van Eijck $\mathrm{CH}$ : Influence of proinflammatory cytokines on the adhesion of human colon carcinoma cells to lung microvascular endothelium. Int J Cancer 112: 943-950, 2004. 
4. Basoglu M, Yildirgan MI, Taysi S, et al: Levels of soluble intercellular adhesion molecule-1 and total sialic acid in serum of patients with colorectal cancer. J Surg Oncol 83: 180-184, 2003.

5. Steeg PS, Ouatas T, Halverson D, Palmieri D and Salerno M Metastasis suppressor genes: basic biology and potential clinical use. Clin Breast Cancer 4: 51-62, 2003.

6. Lee JH, Miele ME, Hicks DJ, et al: KiSS-1, a novel human malignant melanoma metastasis-suppressor gene. J Natl Cancer Inst 88: 1731-1737, 1996.

7. Lee JH and Welch DR: Suppression of metastasis in human breast carcinoma MDA-MB-435 cells after transfection with the metastasis suppressor gene, KiSS-1. Cancer Res 57: 2384-2387, 1997.

8. Lee JH and Welch DR: Identification of highly expressed genes in metastasis-suppressed chromosome 6/human malignant melanoma hybrid cells using subtractive hybridization and differential display. Int J Cancer 71: 1035-1044, 1997.

9. Ohtaki T, Shintani Y, Honda S, et al: Metastasis suppressor gene KiSS-1 encodes peptide ligand of a G-protein-coupled receptor. Nature 411: 613-617, 2001.

10. Kotani M, Detheux M, Vandenbogaerde A, et al: The metastasis suppressor gene KiSS-1 encodes kisspeptins, the natural ligands of the orphan G protein-coupled receptor GPR54. J Biol Chem 276: 34631-34636, 2001.

11. Muir AI, Chamberlain L, Elshourbagy NA, et al: AXOR12, a novel human $\mathrm{G}$ protein-coupled receptor, activated by the peptide KiSS-1. J Biol Chem 276: 28969-28975, 2001.

12. Ikeguchi M, Yamaguchi K and Kaibara N: Clinical significance of the loss of KiSS-1 and orphan G-protein-coupled receptor (hOT7T175) gene expression in esophageal squamous cell carcinoma. Clin Cancer Res 10: 1379-1383, 2004.

13. Dhar DK, Naora H, Kubota H, et al: Downregulation of KiSS-1 expression is responsible for tumor invasion and worse prognosis in gastric carcinoma. Int J Cancer 111: 868-872, 2004

14. Masui T, Doi R, Mori T, et al: Metastin and its variant forms suppress migration of pancreatic cancer cells. Biochem Biophys Res Commun 315: 85-92, 2004.

15. Sanchez-Carbayo M, Capodieci P and Cordon-Cardo C: Tumor suppressor role of KiSS-1 in bladder cancer: loss of KiSS-1 expression is associated with bladder cancer progression and clinical outcome. Am J Pathol 162: 609-617, 2003.

16. Stark AM, Tongers K, Maass N, Mehdorn HM and Held-Feindt J: Reduced metastasis-suppressor gene mRNA-expression in breast cancer brain metastases. J Cancer Res Clin Oncol 131: 191-198, 2005.

17. Chirco R, Liu XW, Jung KK and Kim HR: Novel functions of TIMPs in cell signaling. Cancer Metastasis Rev 25: 99-113, 2006.

18. Freije JM, MacDonald NJ and Steeg PS: Nm23 and tumour metastasis: basic and translational advances. Biochem Soc Symp 63: 261-271, 1998
19. Stafford LJ, Vaidya KS and Welch DR: Metastasis suppressors genes in cancer. Int J Biochem Cell Biol 40: 874-891, 2008.

20. Rinker-Schaeffer CW, O'Keefe JP, Welch DR and Theodorescu D: Metastasis suppressor proteins: discovery, molecular mechanisms, and clinical application. Clin Cancer Res 12: 3882-3889, 2006.

21. Vaidya KS and Welch DR: Metastasis suppressors and their roles in breast carcinoma. J Mammary Gland Biol Neoplasia 12: 175-190, 2007.

22. Bodenstine TM and Welch DR: Metastasis suppressors and the tumor microenvironment. Cancer Microenviron 1: 1-11, 2008.

23. Hori A, Honda S, Asada M, et al: Metastin suppresses the motility and growth of $\mathrm{CHO}$ cells transfected with its receptor. Biochem Biophys Res Commun 286: 958-963, 2001.

24. Yan C, Wang H and Boyd DD: KiSS-1 represses 92-kDa type IV collagenase expression by down-regulating NF- $\kappa \mathrm{B}$ binding to the promoter as a consequence of IKB $\alpha$-induced block of p65/ p50 nuclear translocation. J Biol Chem 276: 1164-1172, 2001.

25. Kang HS, Baba T, Mandai M, et al: GPR54 is a target for suppression of metastasis in endometrial cancer. Mol Cancer Ther 10: 580-590, 2011.

26. Olbrich T, Ziegler E, Türk G, Schubert A, Emons G and Grundker C: Kisspeptin-10 inhibits bone-directed migration of GPR54-positive breast cancer cells: Evidence for a dose-window effect. Gynecol Oncol 119: 571-578, 2010.

27. Sasaki H, Miura K, Horii A, et al: Orthotopic implantation mouse model and cDNA microarray analysis indicates several genes potentially involved in lymph node metastasis of colorectal cancer. Cancer Sci 99: 711-719, 2008.

28. Schumacher P, Dineen S, Barnett C Jr, Fleming J and Anthony T: The metastatic lymph node ratio predicts survival in colon cancer. Am J Surg 194: 827-831, 2007.

29. Moertel CG: Chemotherapy for colorectal cancer. N Engl J Med 330: 1136-1142, 1994.

30. Nash KT, Phadke PA, Navenot JM, et al: Requirement of KISS1 secretion for multiple organ metastasis suppression and maintenance of tumor dormancy. J Natl Cancer Inst 99: 309-321, 2007.

31. Beck BH and Welch DR: The KISS1 metastasis suppressor: a good night kiss for disseminated cancer cells. Eur J Cancer 46: 1283-1289, 2010.

32. Hou YK, Wang Y, Cong WM and Wu MC: Expression of tumor metastasis-suppressor gene KiSS-1 and matrix metalloproteinase-9 in portal vein tumor thrombus of hepatocellular carcinoma. Ai Zheng 26: 591-595, 2007 (In Chinese).

33. Nash KT and Welch DR: The KISS1 metastasis suppressor: mechanistic insights and clinical utility. Front Biosci 11: 647-659, 2006. 